\title{
Can neutrophil to lymphocyte ratio predict lamina propria invasion in patients with non muscle invasive bladder cancer?
}

\author{
Haci Ibrahim Cimen ${ }^{1}$, Fikret Halis ${ }^{1}$, Hasan Salih Saglam ${ }^{1}$, Ahmet Gokce ${ }^{1}$ \\ ${ }^{1}$ Department of Urology, Sakarya Training and Research Hospital, Sakarya University, Sakarya, Turkey
}

\begin{abstract}
Objective: Recent studies have demonstrated the role of systemic inflammation in the development and progression of cancer. In this study, we evaluated whether preoperatively measured neutrophil-to-lymphocyte ratio (NLR) can predict lamina propria invasion in patients with non-muscle-invasive bladder cancer (NMIBC).

Material and Methods: We reviewed the medical records of 304 consecutive and newly diagnosed patients with bladder cancer who had been treated with transurethral resection between January 2008 and June 2014. In total, 271 patients were included in the study and the patients were divided into two groups according to the pathological stage (Group 1: Ta, Group 2: T1). NLR was calculated by dividing the absolute neutrophil count (N) by the absolute lymphocyte count (L).

Results: In total, 271 patients (27 women and 244 men) were enrolled. Mean age was higher in Group 2 than in Group 1 ( $67.3 \pm 10.8$ vs. $62.9 \pm 10.8$, $p<0.001)$. Furthermore, the presence of high grade tumors and tumors $\geq 3 \mathrm{~cm}$ in size was statistically higher in Group 2 than in Group 1 (70.9\% vs. 9.9\%, $\mathrm{p}=0.0001 ; 71.8 \%$ vs. 36\%, $\mathrm{p}=0.0001$, respectively). While the mean white blood cell (WBC) and $\mathrm{N}$ counts were statistically insignificant $(7.63 \pm 1.87$ vs. $7.69 \pm 1.93, p=0.780 ; 4.72 \pm 1.54$ vs. $4.46 \pm 1.38, p=0.140$; respectively), L was significantly lower and NLR was significantly higher in Group 2 than in Group 1 ( $2.07 \pm 0.75$ vs. $2.4 \pm 0.87, p=0.001 ; 2.62 \pm 1.5$ vs. $2.19 \pm 1.62, p=0.029$; respectively).

Conclusion: Our data indicate that high NLR and low L are statistically associated with $\mathrm{T} 1$ stage, whereas low $\mathrm{L}$ are able to predict lamina propria invasion in patients with NMIBC. These findings suggest that pretreatment measurement of NLR may provide valuable information for the clinical management of patients with NMIBC. Prospective studies are now required to further validate the role of NLR as a risk factor in NMIBC.
\end{abstract}

\section{ARTICLE INFO}

\section{Keywords:}

Urinary Bladder; Neoplasms;

Inflammation

Int Braz J Urol. 2017; 43: 67-72

Submitted for publication:

March 16, 2016

Accepted after revision:

August 24, 2016

Published as Ahead of Print:

November 10, 2016

\section{INTRODUCTION}

Bladder cancer is the most common urinary tract malignancy and the third most common cancer in men, following prostate and lung cancer, with an estimated 58.950 new cases and 11.820 deaths in 2016 alone (1). While 75\%-85\% of the patients with bladder cancer present with a disease confined to the mucosa (stage Ta, CIS) or submucosa (stage $\mathrm{T} 1$ ), the remaining cases may often include bladder cancers that invade the muscle (2). Moreover, it is known that non-muscle-invasive bladder cancer (NMIBC) may progress as $43 \%$ of patients with muscle invasive bladder 
cancer treated with radical cystectomy were initially diagnosed with NMIBC (3). Therefore, identifying NMIBC patients in whom the cancer is more likely to progress is an important issue to consider for in the management of these patients. A risk Table published by the European Organization for Research and Treatment of Cancer (EORTC) previously suggested stratifying patients into low-, intermediate-, and high-risk groups, a strategy designed to help guide the management of these patients (4).

Recent studies have demonstrated the role of systemic inflammation in the development and progression of cancer (5). For example, an elevated neutrophil-to-lymphocyte ratio (NLR) has consistently been found to be associated with muscle-invasive disease, extravesical disease, along with worse overall and disease-free survival rates (6-9). Recently published data have also revealed that an elevated NLR is an independent predictor of disease progression and recurrence in patients with NMIBC (10). The aim of the current study was to evaluate whether preoperatively measurement of NLR can predict lamina propria invasion in patients with NMIBC.

\section{MATERIAL AND METHODS}

This study was approved by the local ethics committee. We retrospectively reviewed the medical records of 304 consecutive and newly diagnosed patients with non muscle invasive bladder cancer treated with transurethral resection between January 2008 and June 2014. Patients with preoperative infection, hematological malignancies and unexplained leukocytosis $(\mathrm{n}=33)$ were excluded from the study. Patients were divided into two groups according to their pathological stage (Group 1: Ta, n=161; Group 2: T1, n=110). From each patient, we obtained preoperative blood data including white blood cell (WBC), neutrophil (N) and lymphocyte counts (L). NLR was calculated by dividing $\mathrm{N}$ by $\mathrm{L}$. The size and number of tumors were determined using preoperative radiological imaging and cyctoscopic examination prior to transuretral resection. Groups were then compared with regard to age, gender, tumor size, tumor number, WBC, N, L, and NLR.

\section{Statistical analyses}

Statistical analyses were performed using the Number Cruncher Statistical System (NCSS) (2007, Utah, USA). Categorical variables were summarized using actual counts and percentages, whereas continuous variables were summarized using the mean \pm SD. Parametric and non parametric variables were evaluated using the t-test and chi-squared test, respectively. Logistic regression analysis was also used to determine predictors of T1 stage tumors. Statistical significance was considered at $\mathrm{p}<0.05$.

\section{RESULTS}

In total, 271 patients were enrolled in this study (27 women and 244 men). Mean age was higher in Group 2 than in Group $1(67.3 \pm 10.8$ vs. $62.9 \pm 10.8, p<0.001)$. The incidence of high grade tumors and tumors $\geq 3 \mathrm{~cm}$ in size was statistically higher in Group 2 than in Group 1 (70.9\% vs. $9.9 \%, p=0.0001 ; 71.8 \%$ vs. $36 \%, p=0.0001$, respectively). While the mean WBC and N counts were statistically insignificant $(7.63 \pm 1.87$ vs. $7.69 \pm 1.93$, $\mathrm{p}=0.780 ; 4.72 \pm 1.54$ vs. $4.46 \pm 1.38, \mathrm{p}=0.140$; respectively), L was significantly lower and NLR was significantly higher in Group 2 than in Group 1 $(2.07 \pm 0.75$ vs. $2.4 \pm 0.87, p=0.001 ; 2.62 \pm 1.5$ vs. $2.19 \pm 1.62, \mathrm{p}=0.029$; respectively) (Table- 1 ).

In order to evaluate the factors that might affect the presence of T1 tumors, we performed logistic regression analysis. High grade tumor $(p=0.001)$, tumor size $(\geq 3 \mathrm{~cm})(p=0.001)$, and $\mathrm{L}(\mathrm{p}=0.049)$ were all associated with $\mathrm{T} 1$ tumors (Table-2).

According to the receiver operating characteristic analysis, the optimum cut-off value for NLR and L was $>1.84$ (area under curve [AUC] 0.616, 95\% CI, 0.556-0.675) and $\leq 2.4$ ([AUC] 0.625, 95\% CI, 0.564-0.683), respectively (Figure-1). Sensitivity for NLR and L was $67.3 \%$ vs. 75.5\%, whereas specificity was $54.1 \%$ vs. $47 \%$, respectively (Table-3).

\section{DISCUSSION}

Non-muscle invasive bladder cancer represents a heterogeneous group of tumors with di- 
Table 1 - Patients characteristics.

\begin{tabular}{|c|c|c|c|c|c|c|}
\hline & & \multicolumn{2}{|c|}{$\begin{array}{l}\text { Group } 1 \\
\text { (Ta, n:161) }\end{array}$} & \multicolumn{2}{|c|}{$\begin{array}{c}\text { Group } 2 \\
(\mathrm{~T} 1, \mathrm{n}: 110)\end{array}$} & $p$ \\
\hline \multicolumn{2}{|l|}{ Age } & \multicolumn{2}{|c|}{$62.9 \pm 10.8$} & \multicolumn{2}{|c|}{$67.3 \pm 10.77$} & $0.001^{\sharp}$ \\
\hline Gender & Man (\%) & 146 & $90.7 \%$ & 98 & $89.1 \%$ & \\
\hline \multirow{3}{*}{ Grade } & Woman (\%) & 15 & $9.3 \%$ & 12 & $10.9 \%$ & 0.667 \\
\hline & PUNLMP (\%) & 51 & $31.7 \%$ & 2 & $1.8 \%$ & \\
\hline & Low Grade (\%) & 94 & $58.4 \%$ & 30 & $27.2 \%$ & \\
\hline \multirow{3}{*}{ Tumor Size } & High Grade (\%) & 16 & $9.9 \%$ & 78 & $70.9 \%$ & 0.0001 \\
\hline & $<3 \mathrm{~cm}(\%)$ & 103 & $64 \%$ & 31 & $28.2 \%$ & \\
\hline & $\geq 3 \mathrm{~cm}(\%)$ & 58 & $36 \%$ & 79 & $71.8 \%$ & 0.0001 \\
\hline \multirow{2}{*}{$\begin{array}{l}\text { Tumor } \\
\text { Number }\end{array}$} & Single Tumor (\%) & 107 & $66.5 \%$ & 68 & $61.8 \%$ & \\
\hline & Multiple Tumor (\%) & 54 & $33.5 \%$ & 42 & $38.2 \%$ & 0.443 \\
\hline \multicolumn{2}{|c|}{ WBC (mean \pm sd) } & \multicolumn{2}{|c|}{$7.69 \pm 1.93$} & \multicolumn{2}{|c|}{$7.63 \pm 1.87$} & $0.780^{¥}$ \\
\hline \multicolumn{2}{|c|}{ Neutrophil $($ mean \pm sd $)$} & \multicolumn{2}{|c|}{$4.46 \pm 1.38$} & \multicolumn{2}{|c|}{$4.72 \pm 1.54$} & $0.140^{¥}$ \\
\hline \multicolumn{2}{|c|}{ Lymphocyte (mean \pm sd) } & \multicolumn{2}{|c|}{$2.4 \pm 0.87$} & \multicolumn{2}{|c|}{$2.07 \pm 0.75$} & $0.001^{¥}$ \\
\hline \multicolumn{2}{|c|}{ NLR $($ mean $\pm s d)$} & \multicolumn{2}{|c|}{$2.19 \pm 1.62$} & \multicolumn{2}{|c|}{$2.62 \pm 1.5$} & $0.029^{*}$ \\
\hline
\end{tabular}

PUNLMP = Papillary urothelial neoplasm of low malignant potential WWBC $=$ White blood cell; $\mathbf{N L R}=$ Neutrophil-to-lymphocyte ratio.

$¥=$ Independent sample $t$ test; $\square=$ chi-square test

Table 2 - Logistic regression analyses for predicting T1 tumors.

\begin{tabular}{|c|c|c|c|c|c|c|}
\hline & \multirow{2}{*}{ B } & \multirow{2}{*}{ S.E. } & \multirow{2}{*}{$p$} & \multirow{2}{*}{$\mathrm{OR}$} & \multicolumn{2}{|c|}{ OR \%95 Cl } \\
\hline & & & & & Lower & Upper \\
\hline Grade & & & 0.001 & & & \\
\hline Grade (Low Grade) & -4.63 & 0.78 & 0.001 & 0.01 & 0.00 & 0.05 \\
\hline Grade (High Grade) & 2.62 & 0.36 & 0.001 & 0.07 & 0.04 & 0.15 \\
\hline Tumor size ( $\geq 3 \mathrm{~cm}$ ) & 1.21 & 0.35 & 0.001 & 0.30 & 0.15 & 0.59 \\
\hline Lymphocyte & -0.41 & 0.21 & 0.049 & 0.66 & 0.44 & 1.00 \\
\hline
\end{tabular}

fferential rates of recurrence and progression (11). The risk of progression primarily depends on the tumor grade, number, and size of tumor (12). Recently published data showed that the EORTC risk model is useful in predicting the progression of NMIBC but also noted the importance of upda- ting new risk markers to improve the risk classification and prediction of progression (13). The current study assessed the predictive value of preoperative blood tests for lamina propria invasion in patients with NMIBC who were treated with TUR. Our analyses showed that low L $(\leq 2.4)$ can 
act as an effective predictor for T1 tumors. While NLR was unable to predict T1 tumors with statistical probability, NLR was statistically higher in patients with T1 tumors than in patients with Ta tumors. Furthermore patients with NLR $>1.8$ exhibited a risk of developing a T1 tumor that was 1.5 times greater.

Increasing evidence supports the involvement of systemic inflammation in the growth and progression of tumors (5). NLR, is a parameter of stress and systemic inflammation, which is readily measurable in substantially ill patients (14). The association of pretreatment NLR and prognosis has also been reported for various other types of cancer, including ovarian cancer, gastric cancer, hepatocellular carcinoma, non-small cell lung cancer, and bladder cancer (15-20). Moreover, preoperative NLR was found to be associated with the progression and recurrence of $\operatorname{NMIBC}(7,10,20)$.

The relationships between increased NLR, and poor prognosis, and advanced stage of tumor can be explained by the impaired immune res- ponse of hosts to the tumor, which is dependent on L (14). Tumor proliferation and the survival of malignant cells ultimately depend on inflammation in the tumor microenvironment, and inflammation is also known to stimulate tumor angiogenesis, invasion, and metastasis (5). In advanced cancer patients, a variety of biological factors such as leukocytosis, lymphocytopenia, and C-reactive protein have been identified as having a definite correlation with prognosis (21). Because neutrophils inhibit the immune system and lymphocytes have a role in cell-mediated immunity in the host, such cellular components may reflect the host inflammatory and immune response (22). This hypothesis was confirmed by the fact that we observed a lower L among patients with $\mathrm{T} 1$ tumors in the present study.

As a result of exposure to carcinogens, the accumulation of mutations, and a reduction in immune function, the incidence of cancer and the prevalence of more advanced tumor stages are more common in elderly patients (23). Aged patients are susceptible to a range of changes that serve to di-

Figure 1 - Assesment of cut off value of neutrophil-to-lymphocyte ratio and lymphocyte counts to predict T1 tumors.

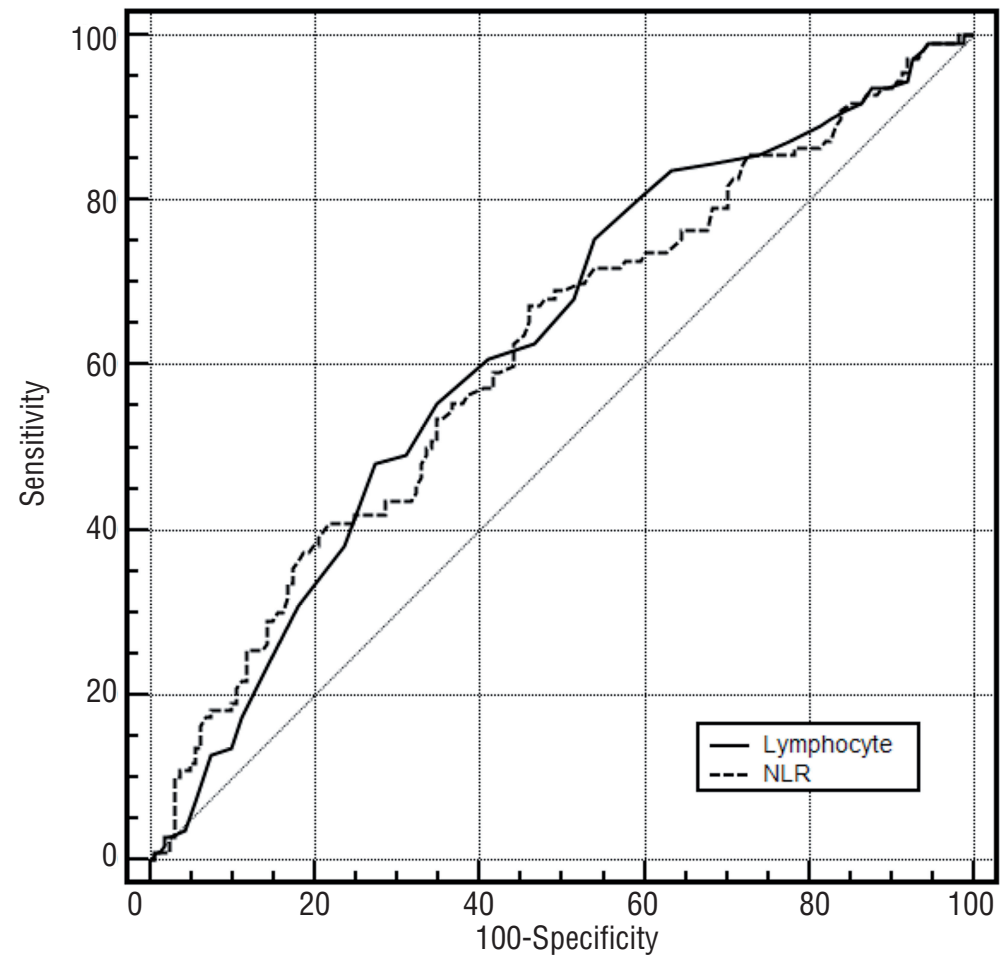


Table 3 - Sensitivity and specificity for NLR and lymphocyte.

\begin{tabular}{lccccc}
\hline Cut off & Sensitivity & Specificity & PPV & NPV & + LR \\
\hline$>1.84$ NLR & 67.27 & 54.04 & 50.0 & 70.7 & 1.46 \\
$\leq 2.4$ Lymphocyte & 75.45 & 46.96 & 48.8 & 73.3 & 1.40 \\
\hline
\end{tabular}

$\mathbf{N L R}=$ Neutrophil-to-lymphocyte ratio; $\mathbf{P P V}=$ Positive predictive value; $\mathbf{N P V}=$ Negative predictive value.

minish immune function such as a reduction in the number of functional B and T cells, modifications in the production and secretion of cytokines, reduced cytotoxic activity of $\mathrm{CD}^{+} \mathrm{T}$ cells, qualitative deficiency of B lymphocytes with reduced response to exogenous antigens, decline in the activity of natural killer cells, and possibly a deficiency in antigen-presenting cells (23). On the other hand, age does not appear to influence L (24). These circumstances indicate that the differences observed between our two study groups in terms of $\mathrm{L}$ and NLR cannot be explained by only age.

To the best of our knowledge this is the first study that evaluated whether preoperative measurement of NLR can predict lamina propria invasion in patients with NMIBC and demonstrated that NLR is statistically higher in T1 tumors than Ta. Moreover, low L counts can predict lamina propria invasion in NMIBC. Our results are likely to be beneficial to surgeons when explaining the risk of progression to patients with NMIBC prior to surgery.

The limitations of our present study include its retrospective nature and the relatively small number of patients studied. These factors may reduce the reliability of our preoperative results. Furthermore, the two groups being compared were statistically different in terms of age. This difference could be considered as a form of selection bias, although we suggest that this difference simply reflects the very nature of bladder cancer as it is well known that advanced age is related to advanced stages of bladder cancer. Moreover, the tumor characteristics were not well described in the operation notes and we had many missing data when we evaluated TURB records. Therefore, we used preoperative radiological imaging and cystoscopic examination together instead TURB records alone.

\section{CONCLUSIONS}

The present study has indicated that high NLR and low L are associated with T1 stage, whereas a low $\mathrm{L}$ is able to predict lamina propria invasion in patients with NMIBC. These findings suggest that pretreatment NLR and L may provide valuable information in the clinical management of patients with NMIBC. Prospective studies between comparable groups are now required to validate the precise role of NLR as a potential risk factor for NMIBC.

\section{CONFLICT OF INTEREST}

None declared.

\section{REFERENCES}

1. Siegel RL, Miller KD, Jemal A. Cancer statistics, 2016. CA Cancer J Clin. 2016Feb;66:7-30.

2. Anastasiadis A, de Reijke TM. Best practice in the treatment of nonmuscle invasive bladder cancer. Ther Adv Urol. 2012:4:13-32.

3. Vaidya A, Soloway MS, Hawke C, Tiguert R, Civantos F. De novo muscle invasive bladder cancer: is there a change in trend? J Urol. 2001;165:47-50.

4. Brausi M, Witjes JA, Lamm D, Persad R, Palou J, Colombel $M$, et al. A review of current guidelines and best practice recommendations for the management of nonmuscle invasive bladder cancer by the International Bladder Cancer Group. J Urol. 2011;186:2158-67.

5. Mantovani A, Allavena P, Sica A, Balkwill F. Cancer-related inflammation. Nature. 2008;454:436-44.

6. Ceylan C, Doluoglu OG, Kele I, Gazel E, Temuçin T, Odaba 0 , et al. Importance of the neutrophil-to-lymphocyte ratio in muscle-invasive and non-muscle invasive bladder tumors. Urologia. 2014;81:120-4.

7. Krane LS, Richards KA, Kader AK, Davis R, Balaji KC, Hemal AK. Preoperative neutrophil/lymphocyte ratio predicts overall survival and extravesical disease in patients undergoing radical cystectomy. J Endourol. 2013;27:1046-50. 
8. Gondo T, Nakashima J, Ohno Y, Choichiro O, Horiguchi $\mathrm{Y}$, Namiki K, et al. Prognostic value of neutrophil-tolymphocyte ratio and establishment of novel preoperative risk stratification model in bladder cancer patients treated with radical cystectomy. Urology. 2012;79:1085-91.

9. Potretzke A, Hillman L, Wong K, Shi F, Brower R, Mai S, et al. NLR is predictive of upstaging at the time of radical cystectomy for patients with urothelial carcinoma of the bladder. Urol Oncol. 2014;32:631-6.

10. Mano R, Baniel J, Shoshany 0, Margel D, Bar-On T, Nativ 0 , et al. Neutrophil-to-lymphocyte ratio predicts progression and recurrence of non-muscle-invasive bladder cancer. Urol Oncol. 2015;33:67.e1-7.

11. Sylvester RJ, van der Meijden AP, Oosterlinck W, Witjes $J A$, Bouffioux C, Denis $L$, et al. Predicting recurrence and progression in individual patients with stage Ta $\mathrm{T} 1$ bladder cancer using EORTC risk tables: a combined analysis of 2596 patients from seven EORTC trials. Eur Urol. 2006;49:466-5.

12. Millán-Rodríguez F, Chéchile-Toniolo G, Salvador-Bayarri J, Palou J, Vicente-Rodríguez J. Multivariate analysis of the prognostic factors of primary superficial bladder cancer. $\mathrm{J}$ Urol. 2000;163:73-8.

13. Busato Júnior WF, Almeida GL, Ribas CA, Ribas Filho JM, De Cobelli 0. EORTC Risk Model to Predict Progression in Patients With Non-Muscle-Invasive Bladder Cancer: Is It Safe to Use in Clinical Practice? Clin Genitourin Cancer. 2016;14:176-82.

14. Zahorec R. Ratio of neutrophil to lymphocyte counts--rapid and simple parameter of systemic inflammation and stress in critically ill. Bratisl Lek Listy. 2001;102:5-14.

15. Gomez D, Farid S, Malik HZ, Young AL, Toogood GJ, Lodge JP, et al. Preoperative neutrophil-to-lymphocyte ratio as a prognostic predictor after curative resection for hepatocellular carcinoma. World J Surg. 2008;32:1757-62.

16. Cho H, Hur HW, Kim SW, Kim SH, Kim JH, Kim YT, et al. Pre-treatment neutrophil to lymphocyte ratio is elevated in epithelial ovarian cancer and predicts survival after treatment. Cancer Immunol Immunother. 2009;58:15-23.

17. Sarraf KM, Belcher E, Raevsky E, Nicholson AG, Goldstraw P, Lim E. Neutrophil/lymphocyte ratio and its association with survival after complete resection in non-small cell lung cancer. J Thorac Cardiovasc Surg. 2009;137:425-8.
18. Yamanaka T, Matsumoto $\mathrm{S}$, Teramukai $\mathrm{S}$, Ishiwata $\mathrm{R}$ Nagai $Y$, Fukushima M. The baseline ratio of neutrophils to lymphocytes is associated with patient prognosis in advanced gastric cancer. Oncology. 2007;73:215-20.

19. Viers BR, Boorjian SA, Frank I, Tarrell RF, Thapa P, Karnes RJ, et al. Pretreatment neutrophil-to-lymphocyte ratio is associated with advanced pathologic tumor stage and increased cancer-specific mortality among patients with urothelial carcinoma of the bladder undergoing radical cystectomy. Eur Urol. 2014;66:1157-64.

20. Ozyalvacli ME, Ozyalvacli G, Kocaaslan R, Cecen K, Uyeturk $U$, Kemahlı E, et al. Neutrophil-lymphocyte ratio as a predictor of recurrence and progression in patients with high-grade pT1 bladder cancer. Can Urol Assoc J. 2015;9:E126-31.

21. Maltoni M, Caraceni A, Brunelli C, Broeckaert B, Christakis N, Eychmueller $\mathrm{S}$, et al. Prognostic factors in advanced cancer patients: evidence-based clinical recommendations--a study by the Steering Committee of the European Association for Palliative Care. J Clin Oncol. 2005;23:6240-8.

22. Kim M, Moon KC, Choi WS, Jeong CW, Kwak C, Kim HH, et al. Prognostic value of systemic inflammatory responses in patients with upper urinary tract urothelial carcinoma. World J Urol. 2015;33:1439-57.

23. Myers CE, Mirza NN, Lustgarten J. Immunity, cancer and aging: lessons from mouse models. Aging Dis. 2011;2:51223.

24. Sparrow D, Silbert JE, Rowe JW. The influence of age on peripheral lymphocyte count in men: a cross-sectional and longitudinal study. J Gerontol. 1980;35:163-6.
Correspondence address: Haci Ibrahim Cimen, MD Department of Urology, Sakarya Training and Research Hospital Sakarya University Sakarya, Sakarya 54100, Turkey E-mail: dr.ibrahimcimen@gmail.com 